\title{
Technical Evaluation of Upgrading a Simple Gas Turbine Fired by Diesel to a Combined Cycle Power Plant in KSA using Design II Software
}

\author{
Salman Obaidoon ${ }^{1}$, Mohamed Hassan ${ }^{1}$ and Omer Bakather ${ }^{1,2}$ \\ ${ }^{1}$ Department of Chemical Engineering, University of Jazan, Jazan, Saudi Arabia \\ ${ }^{2}$ Chemical Engineering Department, Hadhramout University, Hadhramout, Yemen
}

\begin{abstract}
As environmental regulations increase, the need for a clean and inexpensive energy is becoming necessary these days using an available raw material with high efficiency and low emissions of toxic gases. This paper presents a study on modifying a gas turbine power plant fired by diesel, which is located in Saudi Arabia in order to increase the efficiency and capacity of the station as well as decrease the rate of emissions. The studied power plant consists of 30 units with different capacities and total net power is $1470 \mathrm{MW}$. The study was conducted on unit number 25 (GT-25) which produces $72.3 \mathrm{MW}$ with $30.44 \%$ efficiency. In the beginning, the unit was modeled and simulated by using Design II software. In this step, actual unit data were used in order to test the validity of the model. The net power and efficiency obtained from software were $76.4 \mathrm{MW}$ and $32.2 \%$ respectively. A difference of about $6 \%$ was found in the simulated power plant compared to the actual station which means that the model is valid. After the validation of model, the simple gas turbine power plant was converted to a combined cycle power plant (CCPP). In this case, the exhausted gas released from the gas turbine was introduced to a heat recovery steam generator (HRSG), which consists of three heat exchangers: an economizer, an evaporator and a super heater. In this proposed model, optimal operating conditions were used in order to get the highest net power and efficiency. The net power of CCPP was increased to 116.4 MW whereas the overall efficiency of the unit was reached to $49.02 \%$, consuming the same amount of fuel for the gas turbine power plant. For the purpose of comparing the rate of emissions of carbon dioxide on each model. It was found that the rate of $\mathrm{CO}_{2}$ emissions was decreased from $15.94 \mathrm{~kg} / \mathrm{s}$ to $11.61 \mathrm{~kg} / \mathrm{s}$ by using the combined cycle power model as a result of reducing of the amount of diesel from $5.08 \mathrm{~kg} / \mathrm{s}$ to $3.7 \mathrm{~kg} / \mathrm{s}$ needed to produce $76.4 \mathrm{MW}$. The results indicate that the rate of emissions of carbon dioxide was decreased by $27.2 \%$ in CCPP compared to the simple gas turbine power plant.
\end{abstract}

Keywords: Combined cycle power plant, efficiency, heat recovery steam generator, simulation, design II software.

\section{Introduction}

Among all of inventions that showed in the history of human being, electricity is considered as one of the most important inventions that served the humanity for what it has provided of facilitating the life and increasing the yield. Electricity can be produced in several ways, such as thermal power plants (TPP), which are regarded as one of the most popular methods of generating electricity [1]. TPP can be classified according to the type of fuel into: nuclear power plants, solar thermal electric plants, fossil fueled power plants (FFPP), etc. [2], where FFPP is a power plant that generates electricity by burning fuel such as natural gas, coal, diesel, etc. Diesel is considered as a commonly used fuel in fossil fuel power plants due to its low price and good performance [3]. There are many techniques of FFPP are applied these days such as simple gas turbine power plant and combined cycle power plant (CCPP), where the gas turbine power plant consists of a compressor, combustion chamber and turbine [4], [5]. The temperature of the combusted gas to the gas turbine is relatively high $\left(900\right.$ to $\left.1400^{\circ} \mathrm{C}\right)$, as well as the temperature of the exhaust gas (flue gas) is also high $\left(450\right.$ to $\left.650^{\circ} \mathrm{C}\right)$ [6]. The efficiency of this cycle is about 30-35\% [7], [8]. The combined cycle power plant is a combination of gas turbine and steam turbine, where the exhaust gas produced from the gas turbine is entered to Heat Recovery Steam Generator (HRSG) in order to produce steam that used as working medium in the steam turbine [9], [10]. In this case the thermal efficiency ranges from $40 \%$ to $60 \%$, depending on the output power of the station [11], [12]. 
This paper aims to study and analyze a modification of gas turbine power plant fired by diesel to a combined cycle power plant using Design II software and then summarize the difference in efficiency and net power in each technique. Various studies have been conducted by using simple gas turbine power plants and combined cycle power plants for different purposes. These studies could be classified into two sections:

Studies that are interested in efficiency of power plants such as Hossain et al. [6], who studied the possibility of constructing combined cycle power plant over the simple gas turbine power plants in Bangladesh. To achieve his objective, real data of simple and combined cycles were collected from Chandpur 163 MW power plant and have been simulated by using "RETScreen" software. The results showed that when the combined cycle power plant was used, the average efficiency of simple gas turbine power plant was increased from about (25-35) \% to about (40-50) $\%$ in case of combined cycle power plant. Mokhtar et al. [13], conducted a thermodynamic analysis of GARRI (1) combined cycle power plant working with efficiency $27.4 \%$. The simulation and optimization were done by using ASPEN HYSYS. Different scenarios of operating parameters were made by assuming some assumptions. At the end, they concluded that efficiency obtained from ASPEN HYSYS simulator is $31.89 \%$, whereas the optimum efficiency obtained also from ASPEN HYSYS simulator is $33.88 \%$. Another comprehensive study of combined cycle gas turbine CCGT system has been conducted by Ibrahim et al. [14], modeling analysis has been offered in order to develop the performance of CCGT power plant. MATLAB 10A software was used for the simulation. In order to estimate the results, a statistical tool named ANOVA was used. At the end, they found out that the highest thermal efficiency is $61 \%$. Polyzakis et al. [15], studied four different gas turbines cycles in order to optimize a combined cycle power plant with total net power is $300 \mathrm{MW}$ (200 MW from the gas turbine and 100 MW from the steam turbine). The highest thermal efficiency was obtained in reheated gas turbine as a result of high temperature of the exhaust gas. The overall efficiency of combined cycle power plant reached to 53.5\%. Ersayin and Ozgener [16], have analyzed the performance of combined cycle power plant in Turkey named ATAER Energy Power Plant, which gives 119.2 MW. The analysis has been done by using first and second laws of the thermodynamics. Finally, they found that the efficiency of the power plant was 56\%. Another deep study for the purpose of optimization of combined cycle power plant conducted by Xiang and Chen, [17]. The study aimed to increase the efficiency of a CCPP. To achieve this purpose, the study suggested optimizing the HRSG. The results showed that the efficiency of steam cycle rose from $38.6 \%$ to $39.2 \%$, when the high pressure (HP) and intermediate pressure (IP) were reached to the optimal value.

The second section of the literature review is concerned in papers that are interested in emissions of power plants such as Hossain et al. [6], who found that the $\mathrm{CO}_{2}$ emissions of the gas-fired power plant were only $40 \%$ of the coal-fired power plant. In the same field, Ray [18], studied the combined cycle plants in north America. Ray mentioned that combined cycle plants emitted significantly fewer emissions of carbon dioxide $\left(\mathrm{CO}_{2}\right)$, sulfur dioxides $\left(\mathrm{SO}_{2}\right)$, nitrogen oxides $\left(\mathrm{NO}_{\mathrm{x}}\right)$ and other air emissions. $\mathrm{CO}_{2}$ emissions from power plants using combined cycle technology were about 50 percent lower than most coal-fired plants.

\section{Theory and Methodology}

\subsection{Case Study: Power Plant Unit in Saudi Arabia 72.3 MW}

The studied power plant is located in the southern of the country and consists of 30 units. The station fired by diesel fuel and the total net power produce is $1470 \mathrm{MW}$. The study was conducted in unit number 25 (GT-25), which produces $72.3 \mathrm{MW}$ with $29.5 \%$ efficiency. The schematic diagram of the model is shown in Fig.1.

This technique consists of one simple cycle starts with a compressor, where the air is compressed to high pressure. The air is then mixed with a compressed diesel in the mixer before burning. The fuel and air are then fed together to a combustor chamber. The high temperature products resulting from combustion are then entered to a gas turbine called GT expander, where the turbine is rotated and converts the thermal energy of the fuel to mechanical energy. Therefore, the attached generator to the turbine converts the mechanical energy to an electrical energy. 


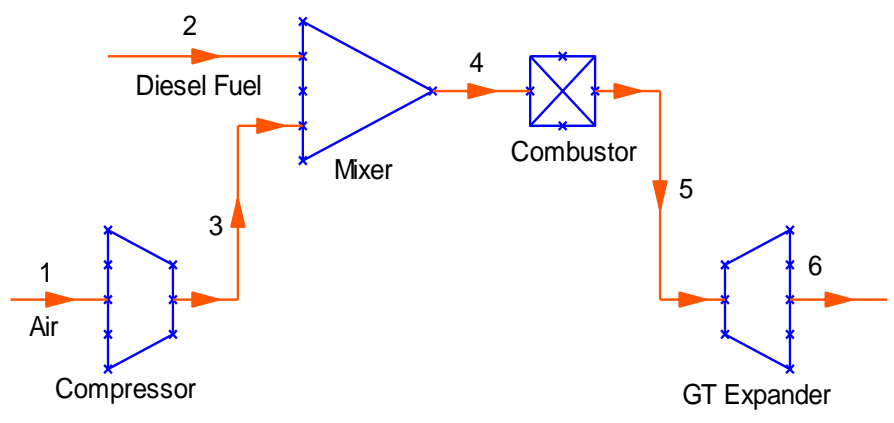

Fig. 1: Simple gas turbine power plant

\subsection{Proposed Model}

With the weakness of efficiency of GT-25 power plant and raising of the emission rates, it has become necessary to improve this system. It was suggested to develop the simple gas turbine power plant by designing new technologies that consume the same amount of raw material and produce higher efficiency and net power as well as lower emission rates. The suggestion was to modify the existing unit (GT-25) from a simple gas turbine power plant to a combined cycle power plant which is considered as the best way of generating electricity by using fossil fuel. The proposed model is shown in Fig. 2.

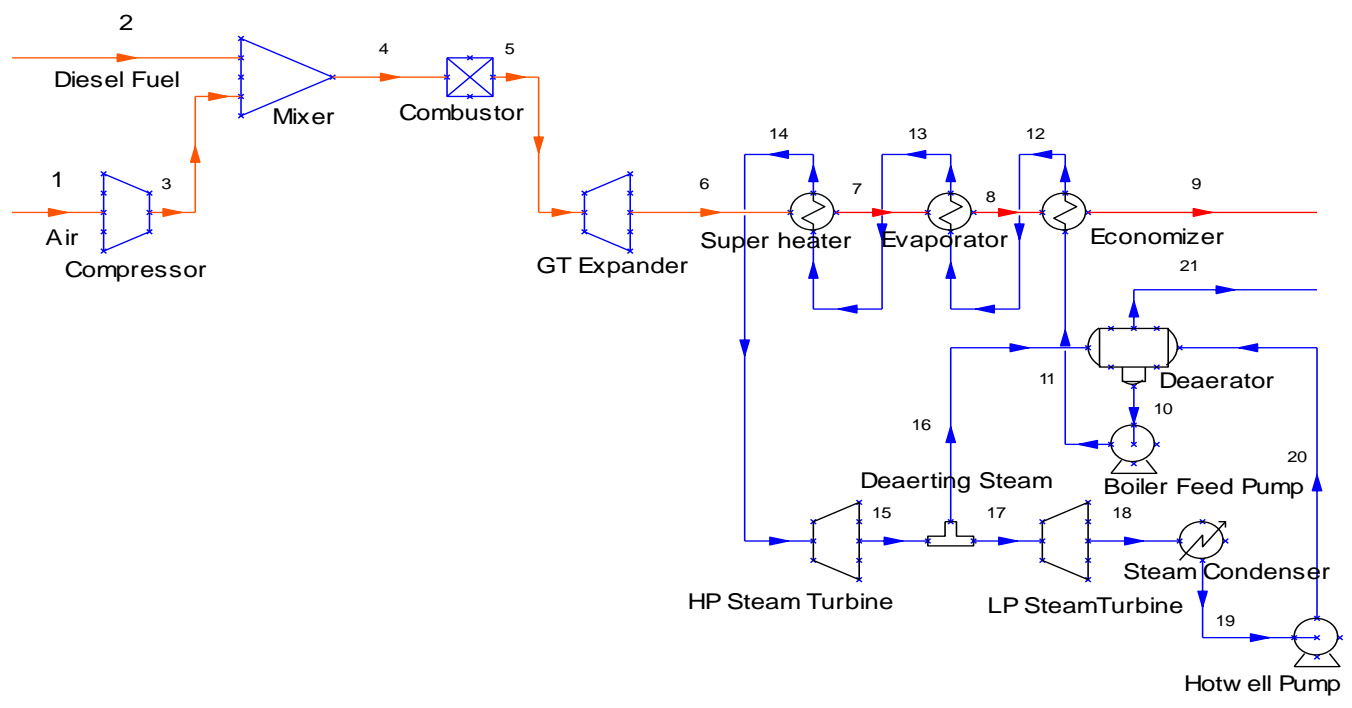

Fig. 2: Combined cycle power plant

In this case, the existing gas turbine power plant is modified, where the exhaust gas from the gas turbine is introduced to the heat recovery steam generator (HRSG) which consists of three heat exchangers: an economizer, an evaporator and a super heater. Water is fed to HRSG, and as a result of the high temperature of the exhaust gas, the water is converted into steam with high temperature and pressure. The steam is first introduced to a high-pressure steam turbine (HP) and then to a low-pressure steam turbine (LP), where more electricity is produced. The steam released from the LP steam turbine is condensed through a steam condenser and pumped to a flash tank called deaerator using hot well pump. Boiler feed pump is then used to pump the water to a heat exchanger called economizer, which is the first unit of HRSG. This water is recycled in the HRSG for reusing again in the cycle. The efficiency of the cycle in this case is about $49.02 \%$, which matches the efficiencies obtained from the literature. 


\section{Results and Discussion}

\subsection{Design II Software}

Design II is a process simulator that designed specifically for Windows computing. It runs both dynamic and steady-state simulation. The software is powerful, comprehensive and easy to use. It offers many features such as Inline FORTRAN. The software database contains 1200 pure components. There is also a crude library that contains 38 world crudes. [21]

\subsection{Simulation of Studied Power Plant (GT-25)}

The actual operating parameters were collected from GT-25 power plant. These data are listed in Table I.

TABLE I: Operating parameters of GT-25 model

\begin{tabular}{cc}
\hline \hline Parameter (unit) & Value \\
\hline Air inlet temperature $(\mathrm{K})$ & 304.15 \\
Air inlet pressure $(\mathrm{atm})$ & 1 \\
Air mass flow rate $(\mathrm{kg} / \mathrm{s})$ & 309.214 \\
Fuel inlet temperature $(\mathrm{K})$ & 306.15 \\
Fuel inlet pressure $(\mathrm{atm})$ & 9.87 \\
Mass flow rate of fuel $(\mathrm{kg} / \mathrm{s})$ & 5.08 \\
Pressure out of compressor $(\mathrm{atm})$ & 10.476 \\
Pressure out of gas turbine $(\mathrm{atm})$ & 1 \\
Isentropic efficiency of compressor & 0.86 \\
Isentropic efficiency of gas turbine & 0.9 \\
\hline \hline
\end{tabular}

The results of simulation for GT-25 model were obtained and summarized in Table II.

TABLE II: Simulation results of GT-25 model

\begin{tabular}{cc}
\hline \hline Property (unit) & Value \\
\hline Outlet temperature of compressor (K) & 632.21 \\
Outlet temperature of gas turbine (K) & 774.59 \\
Compressor used power (MW) & 105.36 \\
Gas turbine produced power (MW) & 181.72 \\
\hline \hline
\end{tabular}

The results show that the net output power of GT-25 power plant is $76.4 \mathrm{MW}$, which is the difference between the power produced in the gas turbine and the power used in the compressor. The efficiency of the model was obtained from dividing the net power by the heat of combustion of the diesel (237.5 MJ/s). The efficiency of this model is $32.2 \%$.

\subsection{Validation of GT-25 Model}

In order to test the validity of the model, the actual results of GT-25 power plant were compared with the simulation results. The net output power of the actual GT-25 power plant was $72.3 \mathrm{MW}$, whereas the efficiency was $30.44 \%$. The software results of the simulated power plant were $76.4 \mathrm{MW}$ and efficiency $32.2 \%$. The difference of results (DR) between the actual model and the simulated model was calculated according to Eq. (1), where SR is simulation results and AR is the actual results of the net output power.

$$
D R=\frac{S R-A R}{S R} \times 100
$$

The difference was about $6 \%$ between the actual results and simulation results of GT-25 model, which mean that the model is valid. This difference is clarified in Fig. 3. 


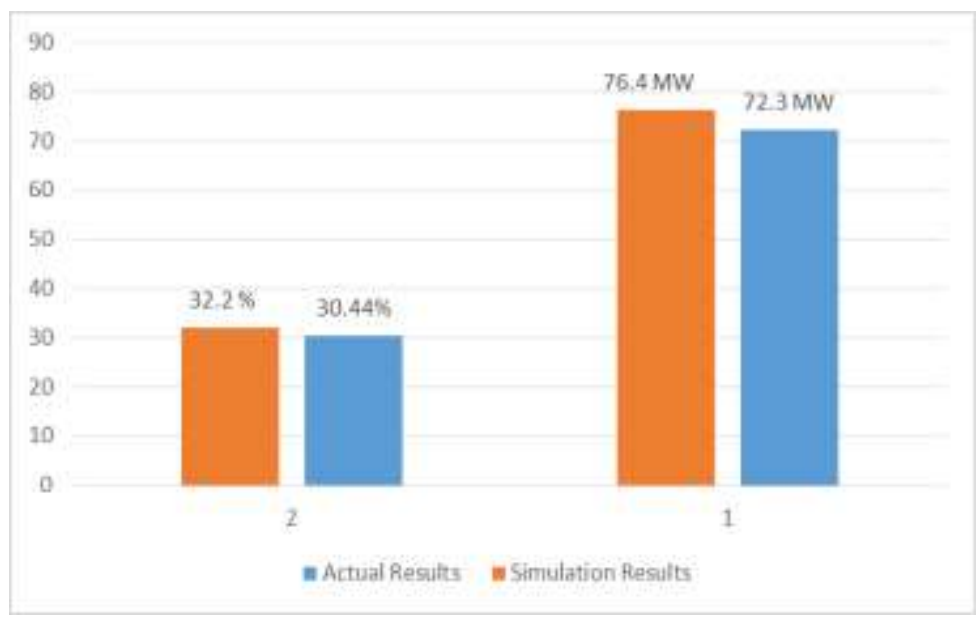

Fig. 3 Comparison between the actual and simulation results

\subsection{Simulation of the Proposed Model}

After the validation of the GT-25 model, the model was extended from a simple gas turbine power plant to a combined cycle power plant. The operating parameters of the gas turbine part were the same as GT-25 model, whereas the operating parameters of the combined cycle are given in Table III.

TABLE III: Operating parameters of the combined cycle model

\begin{tabular}{cc}
\hline \hline Parameters(unit) & Value \\
\hline Temperature of super heater $(\mathrm{K})$ & 763.15 \\
Temperature of condenser $(\mathrm{K})$ & 298.15 \\
Pressure out of HP steam turbine $(\mathrm{atm})$ & 2.8621 \\
Pressure out of LP steam turbine (atm) & 0.0395 \\
Pressure out of boiler feed pump (atm) & 59.22 \\
Mass flow rate of steam (kg/s) & 34.91 \\
Mass flow rate of deaerting steam $(\mathrm{kg} / \mathrm{s})$ & 2.5 \\
Isentropic efficiency of HP turbine & 0.9 \\
Isentropic efficiency of LP turbine & 0.9 \\
Isentropic efficiency of pump & 0.75 \\
\hline \hline
\end{tabular}

The obtained results from software in Table IV show that the properties of combined cycle power plant were more desirable than those obtained in case of simple gas turbine power plant. The total net output power increased from 76.4 MW in case of simple gas turbine power plant to $116.4 \mathrm{MW}$ in CCPP, whereas the efficiency of the CCPP reached to $49.02 \%$.

TABLE II: Operating parameters of the combined cycle model

\begin{tabular}{cc}
\hline \hline Property (unit) & Value \\
\hline Outlet temperature of economizer (K) & 458.8646 \\
Compressor used power (MW) & 105.36 \\
Hotwell pump used power (MW) & 0.04304 \\
Boiler feed pump used power (MW) & 0.271411 \\
Gas turbine produced power (MW) & 181.72 \\
HP turbine produced power (MW) & 22.02 \\
LP turbine produced power (MW) & 18.396 \\
\hline \hline
\end{tabular}




\subsection{Carbon Dioxide Emissions in both Models}

The emissions of carbon dioxide were obtained in each model in order to compare the difference between both models. The emissions of $\mathrm{CO} 2$ in case of simple gas turbine were $15.94 \mathrm{~kg} / \mathrm{s}$, when the station produced 76.4 MW. To obtain the emissions in combined cycle power plant, the amount of diesel of CCPP was decreased in order to acquire the same net output power of the simple gas turbine power plant. When the CCPP consumes $3.7 \mathrm{~kg} / \mathrm{s}$, the net output power decreased to $76.4 \mathrm{MW}$ which is the same of the simple gas turbine power plant. In this case, the emissions of $\mathrm{CO} 2$ were diminished to $11.61 \mathrm{~kg} / \mathrm{s}$. In order to compare the difference between both models, Eq. (2) was used, where DOE represents the difference of emissions, GTE is the gas turbine emissions and CCE means the combined cycle emissions.

$$
D O E=G T E-C C E
$$

The difference of emissions in case of establishing the proposed model was $4.33 \mathrm{~kg} / \mathrm{s}$, which represents the reduction of emissions in CCPP. The percentage of reduction could be calculated according to Eq. (3) in which POR means the percentage of reduction, symbols DOE and GTE have the same meaning as in Eq. (2).

$$
P O R=\left(\frac{D O E \times 100}{G T E}\right)
$$

According to Eq. (3), the percentage of reduction of $\mathrm{CO}_{2}$ in CCPP was $27.2 \%$. This reduction of emissions could be illustrated in Fig. 4.

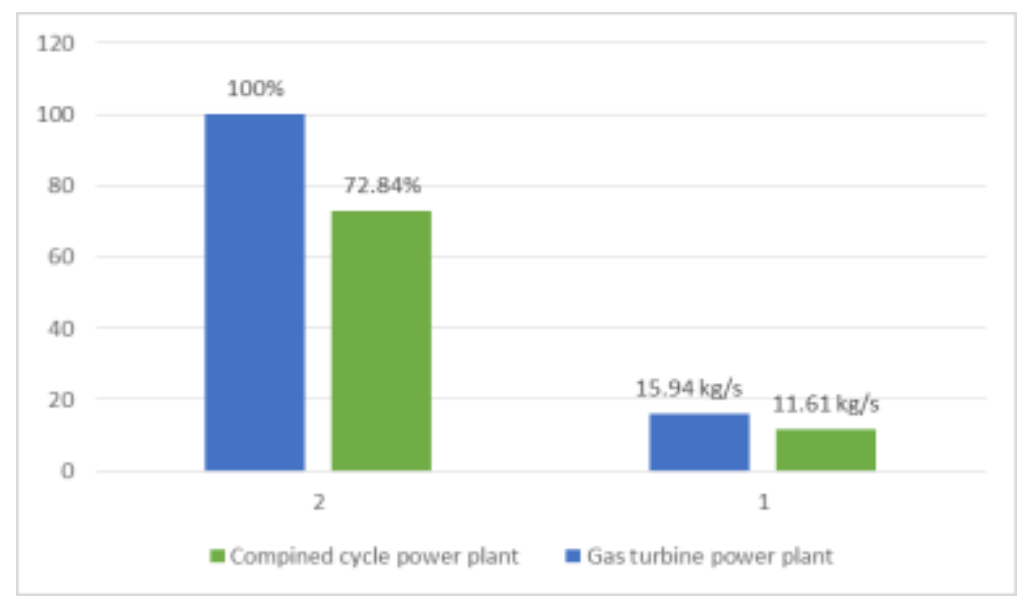

Fig. 4 Comparison the emissions of $\mathrm{CO}_{2}$ in gas turbine power plant and CCPP

The performance of each model could be illustrated in Fig. 5, which represents the differences in total net power, efficiency and the emissions of carbon dioxide in each model.

The results also showed that the amount of fuel used in case of combined cycle power plant is even lower than that needed in simple gas turbine to produce the same total net power. The diesel needed to produce 76.4 MW in gas turbine cycle was $5.08 \mathrm{~kg} / \mathrm{s}$, whereas it consumed $3.7 \mathrm{~kg} / \mathrm{s}$ to produces the same total net power in case of gas turbine cycle. 


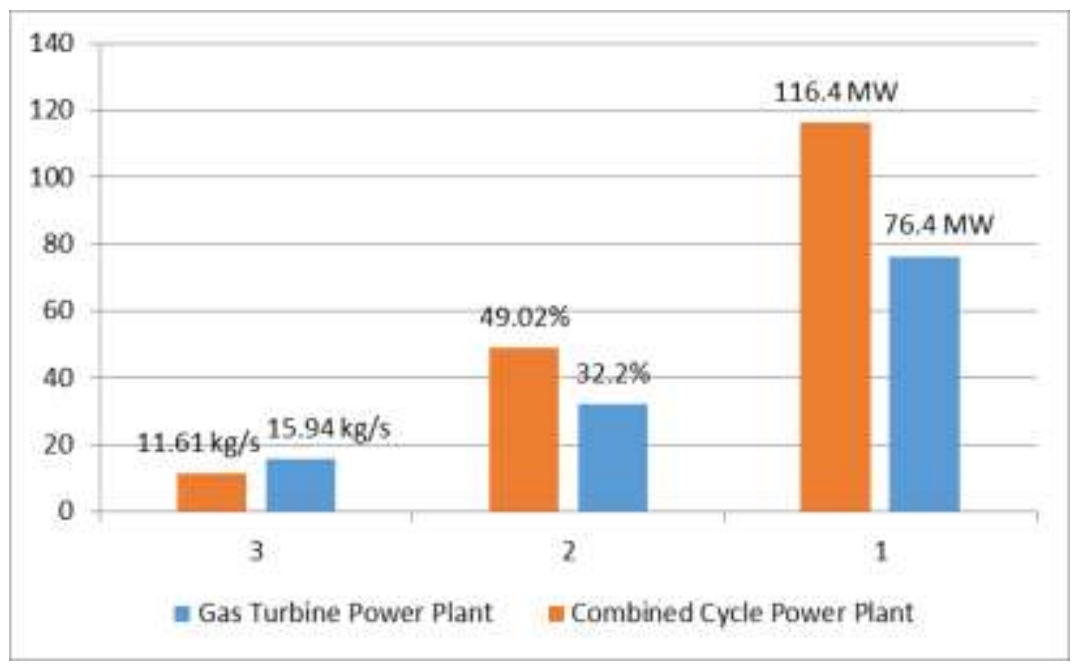

Fig. 5 Comparisons of the performance of simple gas turbine power plant and CCPP

\section{Conclusion}

To analyze the effects of modifying a simple gas power plant to a combined cycle power plant,, a simple gas turbine power plant located in Saudi Arabia was chosen as a case study. The results of the study can be summarized in the following points:

- The net power and efficiency of establishing a combined cycle power plant were increased from 76.4 MW, $32.2 \%$ to $116.4 \mathrm{MW}$ and $49.02 \%$ respectively.

- The rate of emissions of carbon dioxide was reduced from $15.49 \mathrm{~kg} / \mathrm{s}$ in case of a simple gas turbine power plant to $11.61 \mathrm{~kg} / \mathrm{s}$ in the combined cycle power plant with a percent of $27.2 \%$.

- It was recommended to study the rates of (NOx) and (SOx) and a method of treating the exhaust gas.

\section{References}

[1] A. S. B. AL-ANFAJI, "The Optimization of Combined Power - Power Generation Cycles," PhD thesis, School of Engineering \& Technology, University of Hertfordshire, Hatfield, UK, 2014.

[2] D. K. Sarkar, “Thermal Power Plant,” 1st ed. Elsevier, 2015, ch. 2, pp. 39-89.

https://doi.org/10.1016/B978-0-12-801575-9.00002-0

[3] J. M. Robles, "Simulation of a Gas Power Plant," 2002.

[4] T. K. Ibrahim et al., "Thermal performance of gas turbine power plant based on exergy analysis," Appl. Therm. Eng., vol. 115, pp. 977-985, 2017.

https://doi.org/10.1016/j.applthermaleng.2017.01.032

[5] T. K. Ibrahim and M. N. Mohammed, "Thermodynamic Evaluation of the Performance of a Combined Cycle Power Plant," Int. J. Energy Sci. Eng.vol 1, no 2, pp. 60-70, 2015.

[6] M. I. Hossain, I. A. Zissan, M. S. M. Khan, Y. R. Tushar, and T. Jamal, "Prospect of combined cycle power plant over conventional single cycle power plants in Bangladesh: A case study," 1st Int. Conf. Electr. Eng. Inf. Commun. Technol. ICEEICT 2014, no. June, pp. 1-6, 2014.

https://doi.org/10.1109/ICEEICT.2014.6919060

[7] P. Pourbeik, "Modeling of combined-cycle power plants for power system studies," 2003 IEEE Power Eng. Soc. Gen. Meet. (IEEE Cat. No.03CH37491), vol. 3, no. February, pp. 1-6, 2003.

https://doi.org/10.1109/PES.2003.1267338 
[8] Z. Aminov, N. Nakagoshi, T. D. Xuan, O. Higashi, and K. Alikulov, "Evaluation of the energy efficiency of combined cycle gas turbine. Case study of Tashkent thermal power plant, Uzbekistan," Appl. Therm. Eng., vol. 103, pp. 501-509, 2016. https://doi.org/10.1016/j.applthermaleng.2016.03.158

[9] A. Boiler and P. V. Code, American Society of Mechanical Engineers, vol. 10017. 1998.

[10] A. Ticâ, H. Guéguen, D. Dumur, D. Faille, and F. Davelaar, "Design of a combined cycle power plant model for optimization,” Appl. Energy, vol. 98, pp. 256-265, 2012.

https://doi.org/10.1016/j.apenergy.2012.03.032

[11] H. K. Tin and İ. U, "Intelligence Systems in Environmental Management: Theory and Applications,” vol. 113, 2017.

[12] J. Kalina, "Performance improvement of distributed combined cycle plants through modification of structure," Energy Procedia, vol. 129, pp. 105-112, 2017. https://doi.org/10.1016/j.egypro.2017.09.173

[13] A. M. M, M. E. M, and T. A. J, "Thermodynamics Optimization of GARRI ( 1 ) Combined Cycle Power Plant by Using ASPEN HYSYS Simulation,” no. January, pp. 69-78, 2016.

[14] T. k. Ibrahim et al., "The optimum performance of the combined cycle power plant: A comprehensive review," Renew. Sustain. Energy Rev., vol. 79, no. May 2016, pp. 459-474, 2017.

[15] A. L. Polyzakis, C. Koroneos, and G. Xydis, "Optimum gas turbine cycle for combined cycle power plant,” Energy Convers. Manag., vol. 49, no. 4, pp. 551-563, 2008.

https://doi.org/10.1016/j.enconman.2007.08.002

[16] E. Ersayin and L. Ozgener, "Performance analysis of combined cycle power plants: A case study," Renew. Sustain. Energy Rev., vol. 43, pp. 832-842, 2015. https://doi.org/10.1016/j.rser.2014.11.082

[17] W. Xiang and Y. Chen, "Performance improvement of combined cycle power plant based on the optimization of the bottom cycle and heat recuperation,” J. Therm. Sci., vol. 16, no. 1, pp. 84-89, 2007. https://doi.org/10.1007/s11630-007-0084-4

[18] R. Ray, “A report on combined cycle projects in North America," Power Engineering, vol. 118, no. 2, pp. 2-5, 2014.

[19] “WinSim Inc. DESIGN II for Windows." [Online]. Available: https://www.winsim.com/design.html. [Accessed: 18Jan-2018]. 